\title{
Qualidade da água e ictiofauna do córrego São José, Șão Carlos (SP): ênfase nos impactos gerados por lixão desativado
}

\author{
Water quality and fish community in the São José stream, São Carlos (SP): \\ emphasis on the impacts caused by an abandoned waste dump \\ Juliana Cristina de Resende ${ }^{1}$, Jaqueline Santos Santana ${ }^{2}$, Fernanda Teixeira e Marciano ${ }^{3}$, \\ Evaldo Luiz Gaeta Espíndola ${ }^{4}$ \\ ${ }^{1,4}$ Escola de Engenharia de São Carlos, Universidade de São Paulo, São Carlos, Brasil. \\ ${ }^{2}$ Universidade Veiga de Almeida, Rio de Janeiro, Brasil. \\ ${ }^{3}$ JGP Consultoria e Participações, São Paulo, Brasil.
}

\begin{abstract}
Resumo
As atividades antrópicas são responsáveis por modificações estruturais e funcionais nos ecossistemas aquáticos, ocasionando impactos nas comunidades biológicas. O objetivo desta pesquisa foi analisar a ictiofauna do córrego São José, localizado próximo a um lixão desativado no município de São Carlos (SP), e sua estrutura trófica, buscando estabelecer correlações com as características limnológicas do sistema aquático e com as formas de uso e ocupação do solo. Foram realizadas quatro amostragens no ano de 2007 em cinco estações de coleta para determinação da temperatura da água, $\mathrm{pH}$, oxigênio dissolvido, condutividade, formas totais e dissolvidas de fósforo e nitrogênio, além da identificação e classificação trófica da ictiofauna. As famílias Poeciliidae e Characidae foram dominantes, com 43,5\% e 20,2\% das espécies de peixes coletadas, respectivamente. Na estação localizada imediatamente a jusante do lixão, foram observados os maiores valores de condutividade, as maiores concentrações médias de nutrientes e menores concentrações de oxigênio dissolvido. Além disso, nesta estação, houve predominância de espécies de peixes tolerantes à poluição, sobretudo espécies iliófagas e detritívoras. Esses resultados sugerem que, mesmo após mais de 10 anos da desativação do antigo lixão, os resíduos ainda representam uma fonte de contaminação para o córrego.
\end{abstract}

Palavras-chave: Ecossistema aquático, peixes, ecologia trófica, limnologia, resíduos sólidos.

\begin{abstract}
Human activities have been responsible for structural and functional changes in aquatic ecosystems, causing impacts in biological communities. The aim of this research was to analyze the ichthyofauna in the São José Stream, located next to an abandoned waste dump in São Carlos (SP), Brazil, and its trophic structure, looking for relationships among such features, the water physical and chemical characteristics and the land use patterns. Water and fish samples were taken at five sites during four sampling periods in 2007. Water temperature, $p H$, dissolved oxygen, electric conductivity and the concentrations of total and dissolved forms of phosphorus and nitrogen were measured at each sampling site. Poeciliidae and Characidae families were dominant, with $43.5 \%$ and $20.2 \%$ of the fish species collected, respectively. The sampling station located downstream the waste dump showed the highest conductivity values, the highest concentration of all nutrients and low dissolved oxygen concentrations. In addition, at this sampling station, fish species tolerant to pollution were abundant as well as species that were classified in iliophagous and detritivores. These results suggested that, even after more than 10 years of disabling the waste dump, the waste still represents a source of contamination to São José stream.
\end{abstract}

Keywords: Aquatic ecosystem, fish, trophic ecology, limnology, solid waste. 


\section{Introdução}

A qualidade da água e a sua quantidade são constantemente influenciadas por fatores ambientais das bacias hidrográficas (clima, vegetação, geologia, morfologia e uso e ocupação do solo), refletindo não apenas a saúde do ecossistema em si, mas também das paisagens circundantes (MALHEIROS et al., 2012). Uma das principais causas de poluição dos ecossistemas aquáticos é a ausência ou insuficiência de saneamento adequado, resultando no despejo in natura de efluentes industriais e esgoto doméstico nos corpos d'água e na disposição inadequada de resíduos sólidos. Somente no estado de São Paulo, existem ao menos 2000 áreas que foram ou estão sendo utilizadas para disposição de resíduos e poucas apresentam alguma forma de controle ou investigação adequada (ELIS; ZUQUETTE, 2002). Segundo a última Pesquisa Nacional de Saneamento Básico (IBGE, 2010), 50,8\% dos municípios brasileiros ainda depositam os resíduos sólidos em vazadouros a céu aberto (lixões) e $22,5 \%$ em aterros controlados.

Diversos estudos demonstraram que a disposição inadequada de resíduos sólidos é responsável pela contaminação das fontes superficiais de água e principalmente do lençol freático (ATHAYDE JÚNIOR et al., 2008; PORTO et al., 2004; SHINZATO et al., 2012; VELOZO, 2006). No entanto, o conhecimento sobre a duração do processo de contaminação ambiental por estes depósitos de resíduos ainda não está consolidado (SINGH et al., 2009).

Para a implementação de estratégias de controle efetivas dessas fontes de contaminação, é fundamental que seja realizado o monitoramento da qualidade da água dos ecossistemas aquáticos localizados próximos a elas. Mas, para avaliar o impacto de um poluente no ambiente aquático, não basta simplesmente determinar suas concentrações químicas na água, pois as interações entre esses compostos, o meio e a biota não são sempre esclarecidas apenas por essa quantificação. As comunidades bióticas refletem melhor as condições ambientais que as medidas físicas e químicas realizadas isoladamente, uma vez que elas respondem ao resultado da integração dos fatores biogeoquímicos do ambiente (TOGORO, 2006). Segundo Casatti e Ferreira (2009), Karr (1981) e Cunico et al. (2012), dentre os diferentes organismos aquáticos, os peixes são considerados valiosos bioindicadores no nível de organismo, população e de comunidade.

Nesse contexto, o objetivo do presente estudo foi analisar a composição, distribuição, abundância e estrutura trófica da ictiofauna do córrego São José, localizado próximo a um lixão desativado no município de São Carlos (SP), e relacioná-las com as características limnológicas do sistema aquático e com os padrões de uso e ocupação do solo na região.

\section{Material e métodos}

\section{1 Área de estudo}

O córrego São José é um afluente do ribeirão do Feijão, pertence à bacia hidrográfica do rio Jacaré-Guaçu, e se insere na Área de Proteção Ambiental (APA) Corumbataí. Apesar da região em estudo estar situada em uma APA, nota-se a presença expressiva da atividade agropecuária e agroindustrial, com predomínio da cana-de-açúcar.

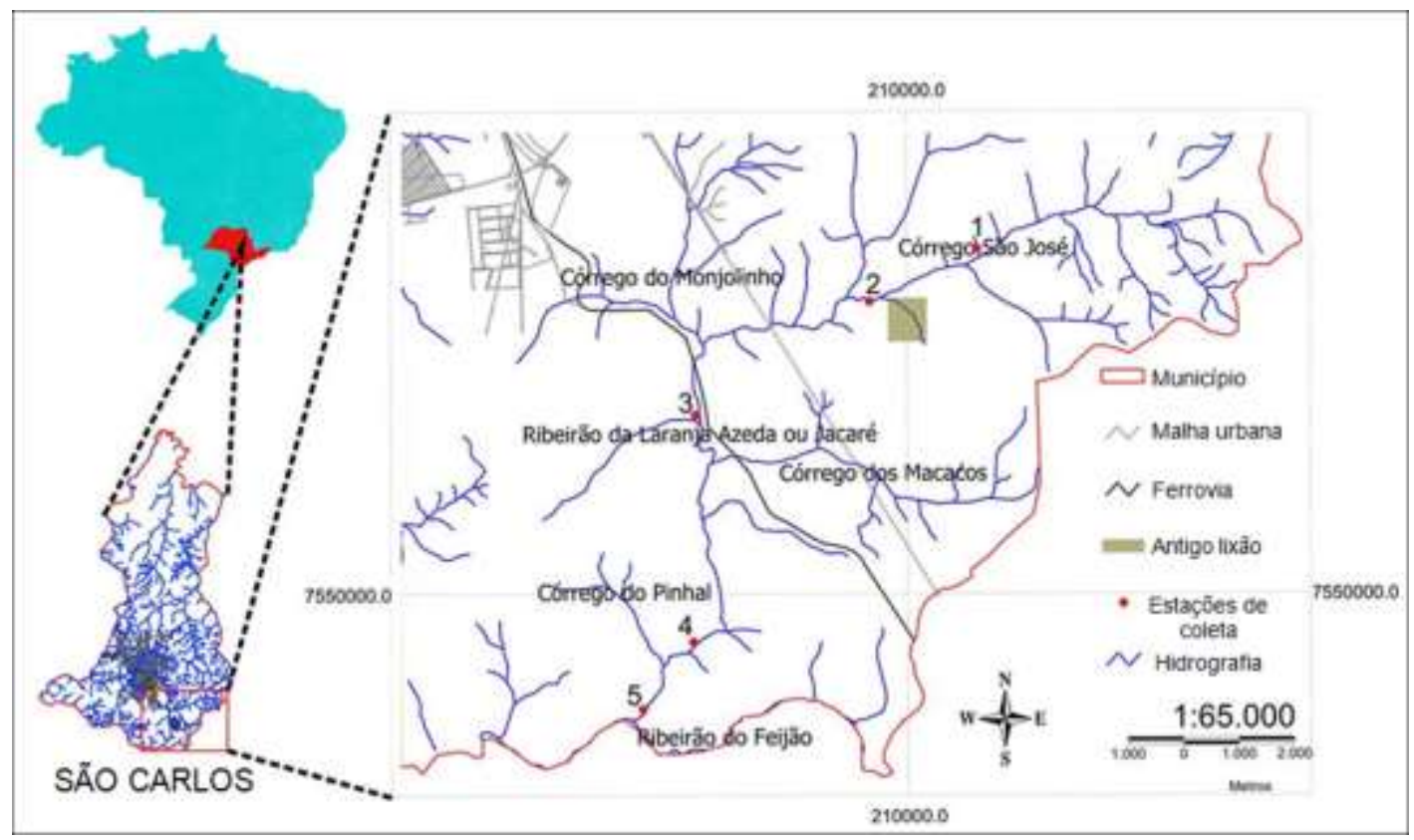

Figura 1. Localização da área de estudo e das cinco estações de coleta. 
Além disso, relevante do ponto de vista ambiental, é a localização do antigo depósito de resíduos sólidos urbanos (lixão) do município de São Carlos na Fazenda Santa Madalena (Figura 1). Cerca de $440.000 \mathrm{~m}^{3}$ de resíduos foram dispostos em uma voçoroca de grandes dimensões por aproximadamente 17 anos (entre 1979 e 1996) sob os solos arenosos permeáveis da Formação Botucatu (detentora do maior manancial brasileiro de águas subterrâneas) sem que fosse instalado um sistema de impermeabilização do solo ou de coleta dos fluidos produzidos a partir da degradação dos resíduos (VELOZO, 2006).

\subsection{Amostragem}

As coletas foram realizadas nos meses de abril, agosto, outubro e dezembro de 2007, tornando possível assim avaliar a sazonalidade das variáveis analisadas. Foram escolhidas cinco estações de coleta distribuídas ao longo de toda a extensão do córrego São José, que segue como córrego Laranja Azeda até sua desembocadura no Ribeirão do Feijão, totalizando uma extensão de 22,23 km (Figura 1). A primeira estação de coleta está localizada próximo à nascente do córrego São José (a montante da área do antigo lixão de São Carlos) e a segunda, logo a jusante desta área. As estações de coleta de 3 a 5 foram escolhidas para avaliar a qualidade da água do córrego após a área de influência do antigo lixão até o deságue no Ribeirão do Feijão, que é uma das principais fontes de abastecimento de água do município de São Carlos (SP) (PMSC, 2010).

\subsection{Variáveis climatológicas e análises físicas e químicas da água}

Os dados de precipitação ( $\mathrm{mm}$ ) e temperatura do ar $\left({ }^{\circ} \mathrm{C}\right)$ durante os meses de coleta foram obtidos na Estação Meteorológica do Centro de Recursos Hídricos e Ecologia Aplicada - EESC/USP.

Em cada uma das estações de coleta, foi realizada a medição da temperatura da água $\left({ }^{\circ} \mathrm{C}\right)$, oxigênio dissolvido $\left(\mathrm{mg} . \mathrm{L}^{-1}\right), \mathrm{pH}$ e condutividade elétrica $\left(\mu \mathrm{S} . \mathrm{cm}^{-1}\right)$ por meio de uma sonda multiparâmetros Horiba, modelo U-10. Além disso, foram determinadas, em laboratório, as concentrações de fósforo total $\left(\mu \mathrm{g} . \mathrm{L}^{-1}\right)$ e nitrogênio orgânico total (mg.L ${ }^{-1}$ ) (GOLTERMAN et al., 1978); nitrito e nitrato $\left(\mu \mathrm{g} . \mathrm{L}^{-1}\right)(\mathrm{MACKERETH}$ et al., 1978); íon amônio $\left(\mu \mathrm{g} . \mathrm{L}^{-1}\right)$ (KOROLEFF, 1976); fosfato total dissolvido e fosfato inorgânico ( $\left.\mu \mathrm{g} . \mathrm{L}^{-1}\right)$ (APHA, 1995).

\subsection{Coleta e análise da ictiofauna}

A coleta da ictiofauna foi realizada com uma peneira com malha de $2 \mathrm{~mm}$, padronizando-se dez lances consecutivos sem peixes para encerrar a coleta (RIBEIRO, 1994). O tamanho da área amostrada para a coleta dos peixes variou de acordo com as características de cada estação de coleta, de modo a representar os segmentos poço, corredeira e canal. Na estação de coleta 1, localizada próximo à nascente do córrego, as espécies foram encontradas apenas na área de poço. Os indivíduos capturados foram acondicionados em sacos plásticos contendo as informações sobre a época de coleta, o tipo de aparelho utilizado e o ponto em que foi capturado. Em seguida, foram congelados para que pudessem ser identificados em laboratório com auxílio de chaves de identificação (BRITSKI et al., 1984; CASTRO et al., 2004).

A abundância e o número de espécies foram utilizados para calcular o Índice de Diversidade de Shannon $\left(\mathrm{H}^{\prime}\right)$, segundo Krebs (1989) e Magurran (1989):

$$
H^{\prime}=-\sum_{i=1}^{S} p_{i} \ln p_{i}
$$

Em que:

$p_{i}$ : abundância relativa (proporção) da espécie i na $\operatorname{amostra}=n_{i} / N$;

$\mathrm{n}_{\mathrm{i}}$ : número de indivíduos da espécie $\mathrm{i}$;

$\mathrm{N}$ : número total de indivíduos na amostra.

Para reconhecer quais foram as espécies de maior dominância no córrego, aplicou-se o Índice Ponderal de Dominância, que considera a contribuição do número de indivíduos capturados e a biomassa correspondente (BEAUMORD, 1991):

$$
\text { ID }(\%)=\frac{\left(\mathrm{N}_{\mathrm{i}} * \mathrm{P}_{\mathrm{i}}\right)}{\sum\left(\mathrm{N}_{\mathrm{i}} * \mathrm{P}_{\mathrm{i}}\right)} \times 100
$$

Em que:

ID (\%): Índice Ponderal de Dominância;

$\mathrm{N}_{\mathrm{i}}$ : número de indivíduos capturados da espécie $\mathrm{i}$; espécie i.

$\mathrm{P}_{\mathrm{i}}$ : peso total dos indivíduos capturados da

Em seguida, as espécies foram classificadas da seguinte maneira:

ID $(\%) \geq 1 \%$ : Espécies dominantes nância

$0,01 \%<$ ID $(\%)<1 \%$ : Espécies de baixa domi-

ID $(\%) \leq 0,01 \%$ : Espécies raras

As paredes dos estômagos dos peixes foram lavadas com formol $4 \%$ para a retirada total do conteúdo estomacal. Posteriormente, este conteúdo foi analisado em microscópio estereoscópico para a identificação e quantificação dos itens alimentares, determinando-se a frequência de ocorrência, o volume (método volumétrico) e o peso seco de cada item encontrado (método gravimétrico). A importância dos itens na dieta das espécies estudadas foi avaliada pelo Índice Alimentar de Kawakami e Vazzoller (1980):

$$
I_{i}=\frac{F_{i} * P_{i}}{\sum_{i=1}^{n}\left(F_{i} * P_{i}\right)} \times 100
$$


Em que:

IA $_{i}$ : índice alimentar do item i (\%);

$i=1,2, \ldots n$ itens alimentares;

$\mathrm{F}_{\mathrm{i}}$ : frequência de ocorrência do item i (\%);

$\mathrm{P}_{\mathrm{i}}$ : peso relativo do item $\mathrm{i}(\%)$.

\subsection{Análises estatísticas}

Análises exploratórias multivariadas (MANOVA), com nível de confiança de $95 \%$ ( $\mathrm{p} \leq 0,05)$, além de testes univariados, foram realizados para verificar a possível existência de diferença significativa entre as épocas sazonais de coleta. Para isso, foram consideradas, como réplicas, as diferentes estações de coleta amostradas em cada período. Como não houve diferença significativa entre os períodos de coleta $(p>0,05)$, foi aplicada uma Análise de Componentes Principais (PCA) com todo o conjunto de dados, considerando as quatro coletas simultaneamente. As análises estatísticas foram efetuadas no software Statistica 6.0.

\section{Resultados e discussão}

\subsection{Variáveis climatológicas e limnológicas}

Considerando os meses em que foram realizadas as coletas, observaram-se os menores valores de precipitação mensal acumulada em abril $(95,6 \mathrm{~mm})$ e agosto (zero $\mathrm{mm})$ e os maiores em outubro $(129,8 \mathrm{~mm})$ e dezembro de 2007 (125,9 mm). Em relação à temperatura do ar, a menor temperatura média foi observada no mês de agosto $\left(19,7^{\circ} \mathrm{C}\right)$ e a maior, em abril de $2007\left(22,8^{\circ} \mathrm{C}\right)$. A temperatura da água variou de forma similar entre os pontos de coleta durante o período estudado, sendo observado, assim como para a temperatura do ar, maiores valores no mês de abril $\left(23,4^{\circ} \mathrm{C}\right)$ e menores em agosto $\left(20,1^{\circ} \mathrm{C}\right)$ (Tabela 1$)$.

Apesar das variações na temperatura e nível pluviométrico durante o período estudado, verificou-se, considerando o nível de probabilidade aceito de 5\% $(p \leq 0,05)$, que a sazonalidade não foi estatisticamente significativa para o conjunto de dados $(\mathrm{p}=0,122)$. O efeito das estações de coleta sobre o conjunto total de dados também não foi significativo ( $p>0,05)$. No entanto, ao avaliar separadamente cada uma das variáveis (ANOVA), seis delas apresentaram diferença significativa entre as estações: condutividade ( $\mathrm{p}=0,000 ; \mathrm{F}=37,147)$, nitrogênio total ( $\mathrm{p}=0,045 ; \mathrm{F}=3,170)$, nitrito $(\mathrm{p}=0,000 ; \mathrm{F}=108,160)$, amônia $(\mathrm{p}=0,000 ; \mathrm{F}=69,964)$, fosfato total dissolvido $(\mathrm{p}=0,002$; $\mathrm{F}=7,559)$ e fosfato inorgânico ( $\mathrm{p}=0,002 ; \mathrm{F}=7,165)$.

Uma vez que a componente sazonal não foi considerada estatisticamente significativa $(p>0,05)$, aplicou-se uma Análise de Componentes Principais (PCA) para o conjunto total dos dados, considerando as quatro coletas. Nove variáveis explicaram a distribuição dos dados limnológicos no sistema estudado. O Componente 1, composto por nitrito, amônia, fósforo total dissolvido, condutividade, fosfato inorgânico e nitrogênio total, foi responsável pela explicação de 59,92\% da variância dos dados limnológicos e o Componente 2, composto por oxigênio dissolvido, fósforo total e temperatura da água, por 22,16\% (Tabela 2).

Durante o período estudado, as concentrações de oxigênio dissolvido variaram entre $3,79 \mathrm{mg} \cdot \mathrm{L}^{-1}$ (estação 2 em outubro) e 10,04 mg.L-1 (estação 4 em agosto). Embora não tenha sido verificada diferença significativa entre as estações de coleta $(p>0,05)$, observou-se uma diminuição da concentração de oxigênio dissolvido entre a estação de coleta 1 (concentração média de $7,35 \mathrm{mg} \cdot \mathrm{L}^{-1}$ ), localizada a montante do antigo lixão de São Carlos, e a estação 2 (concentração média de 5,38 mg. $\mathrm{L}^{-1}$ ), localizada a jusante. Além disso, a estação de coleta 2 apresentou, nos meses de outubro e dezembro, valores de oxigênio dissolvido abaixo do limite estabelecido pela Resolução CONAMA 357/05 para rios de classe 2 (até $5 \mathrm{mg} . \mathrm{L}^{-1}$ ) (BRASIL, 2005). Provavelmente, estes valores, obtidos no período chuvoso, estão relacionados à ressuspensão dos sedimentos do fundo do rio, em razão do aumento da vazão, como também ao aporte de matéria orgânica decorrente de sua localização a jusante do antigo lixão. Elevadas concentrações de matéria orgânica e nutrientes levam ao aumento da atividade bacteriana e consequentemente ao consumo de oxigênio disponível, contribuindo para a desoxigenação da água (VON SPERLING, 2005).

Os critérios de proteção à vida aquática estabelecidos pela Resolução CONAMA 357/05 fixam o pH entre 6 e 9 para rios de classe 2 (BRASIL, 2005). No caso do córrego São José, os valores de $\mathrm{pH}$ das estações 2 e 3, na coleta do mês de abril, e 4 e 5, nas coletas de abril e outubro, foram inferiores a 6,0. Já nas demais coletas, os valores de $\mathrm{pH}$ atenderam à Resolução anteriormente mencionada. Tal variável está relacionada ao tipo de solo que drenam os córregos, que no caso da bacia do alto Jacaré-Guaçu drena solos de Cerrado, cujo pH é baixo, resultando em águas com características ácidas (PRADO et al., 1981).

A concentração média da condutividade na estação de coleta 1, localizada a montante da área do antigo depósito de resíduos sólidos, foi de $28,4 \mu \mathrm{S}$. $\mathrm{cm}^{-1}$. Já na estação de coleta 2, localizada logo a jusante da área, a concentração média da condutividade foi de $70 \mu \mathrm{S} . \mathrm{cm}-1$. Esta elevação nos valores de condutividade no córrego após receber a contribuição do antigo depósito de resíduos sólidos pode estar relacionada com o grande aporte de matéria orgânica no sistema e com os elevados valores de nutrientes encontrados na estação de coleta 2. Pôde-se observar também que houve diminuição nos valores de condutividade e aumento da concentração de oxigênio dissolvido da estação 2 para a 3, mantendo-se relativamente estável até a estação 5 , verificando-se assim uma possível capacidade de autodepuração do córrego.

As maiores concentrações médias de todas as formas nitrogenadas e fosfatadas também ocorreram na estação 
Tabela 1. Valores mínimos (Mín.) e máximos (Máx.), médias e desvios padrão das variáveis analisadas [temperatura da água $\left({ }^{\circ} \mathrm{C}\right), \mathrm{pH}$, oxigênio dissolvido $\left(\mathrm{mg} . \mathrm{L}^{-1}\right)$, condutividade elétrica $\left(\mu \mathrm{S} . \mathrm{cm}^{-1}\right)$, nitrogênio total $\left(\mathrm{mg} . \mathrm{L}^{-1}\right)$, fósforo total $\left(\mu \mathrm{g} . \mathrm{L}^{-1}\right)$, nitrato $\left(\mu \mathrm{g} . \mathrm{L}^{-1}\right)$, nitrito $\left(\mu \mathrm{g} . \mathrm{L}^{-1}\right)$, amônia $\left(\mu \mathrm{g} . \mathrm{L}^{-1}\right)$, fosfato total dissolvido $\left(\mu \mathrm{g} . \mathrm{L}^{-1}\right)$ e fosfato inorgânico

( $\left.\mu \mathrm{g} \cdot \mathrm{L}^{-1}\right)$ ] no córrego São José (São Carlos, SP) nas coletas de abril, agosto, outubro e dezembro de 2007.

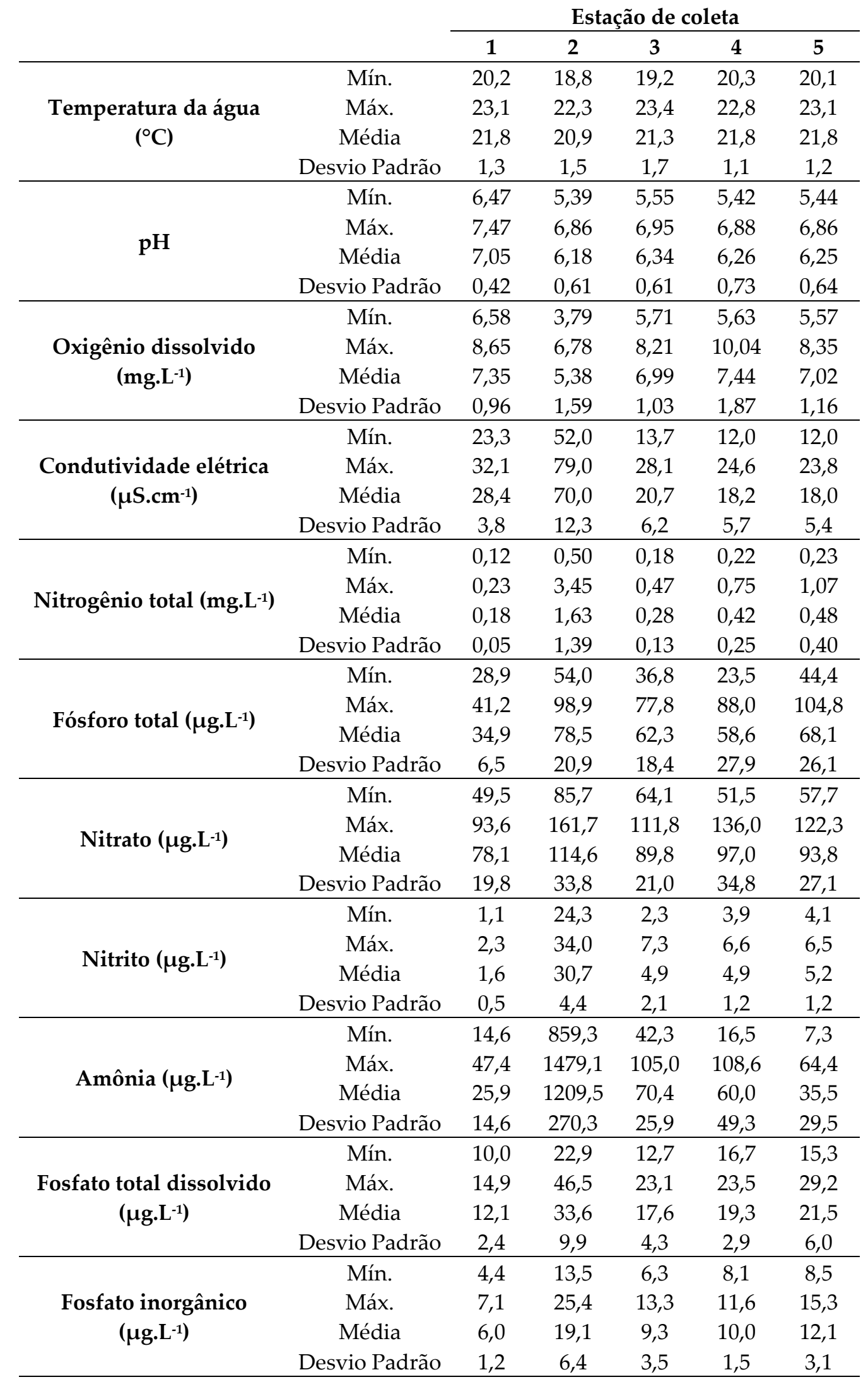


Tabela 2. Porcentagem total de variância explicada pelos componentes principais (1 e 2) e correlações entre esses componentes e as variáveis da água selecionadas.

\begin{tabular}{ccc}
\hline Variáveis selecionadas & Componente 1 & Componente 2 \\
\hline Nitrito & 0,966 & 0,157 \\
Amônia & 0,965 & 0,045 \\
Fosfato total dissolvido & 0,917 & $-0,188$ \\
Condutividade & 0,901 & 0,010 \\
Fosfato inorgânico & 0,891 & $-0,064$ \\
Nitrogênio total & 0,742 & $-0,476$ \\
Oxigênio dissolvido & $-0,472$ & $-0,780$ \\
Fósforo total & 0,385 & 0,764 \\
Temperatura da água & $-0,400$ & 0,713 \\
\hline \% de variância explicada & 59,92 & 22,16 \\
\hline Total & $82,08 \%$ & \\
\hline
\end{tabular}

localizada a jusante do antigo lixão de São Carlos. Já as menores concentrações médias de nutrientes ocorreram na estação 1, que é a mais próxima da nascente e a montante do antigo lixão, corroborando o que foi verificado anteriormente por Rios (1993), Teixeira (1993) e Gadotti (1997) nesse córrego. Esses resultados reforçam o que foi observado por Allan (1995), que afirmou que as concentrações de nutrientes nitrogenados e fosfatados apresentam relação direta com o uso e a ocupação do solo na bacia hidrográfica.

A maior concentração de fósforo total foi obtida na estação de coleta 5 no mês de dezembro $\left(104,8 \mu \mathrm{g} . \mathrm{L}^{-1}\right)$, sendo este o único valor que ultrapassou o limite estabelecido pela Resolução CONAMA 357/05, que corresponde a $100 \mu \mathrm{g} . \mathrm{L}^{-1}$ (BRASIL, 2005). A concentração de nitrogênio total no córrego São José variou de $0,18 \mathrm{mg} \cdot \mathrm{L}^{-1}$ (estação 1) a $3,45 \mathrm{mg} \cdot \mathrm{L}^{-1}$ (estação 2). A maior fração das formas dissolvidas de nitrogênio encontrou-se na forma de amônia, cujos limites superior e inferior foram, respectivamente, $1.479,1 \mu \mathrm{g} . \mathrm{L}^{-1}$ (estação 2) e 7,3 $\mu \mathrm{g} . \mathrm{L}^{-1}$ (estação $5)$, e a menor, na forma de nitrito, que variou de 1,1 $\mu \mathrm{g} . \mathrm{L}^{-1}$ (estação 1) a 34,0 $\mu \mathrm{g} \cdot \mathrm{L}^{-1}$ (estação 2). Argenton (2004) avaliou a qualidade da água no córrego Agua Branca, localizado na mesma bacia hidrográfica do córrego São José, e obteve concentração máxima de amônia de 719,4 $\mu \mathrm{g} . \mathrm{L}^{-1}$. Esse curso de água recebe o efluente da Estação de Tratamento de Esgoto do município de Itirapina (SP) e do esgoto de duas penitenciárias. No caso do córrego avaliado nesta pesquisa, a concentração de amônia foi ainda maior, $1.479,1 \mu \mathrm{g} . \mathrm{L}^{-1}$, o que reflete uma condição crítica para essa variável. A amônia está associada ao lixiviado de lixões e aterros sanitários, sendo uma variável-alvo frequente em processos de tratamento e remediação deste efluente (KULIKOWSKA; KLIMIUK, 2008; SHALINI; JOSEPH, 2012).

A distribuição espacial dos dados evidencia que as estações 3, 4 e 5 apresentaram maior semelhança entre si, estando as estações 1 e 2 isoladas deste grupo (Figura 2). A estação 1, que corresponde ao ponto mais próximo à nascente do córrego, apresentou a menor concentração média para todos os nutrientes analisados. Além disso, para todas as variáveis, com exceção da temperatura da água, esta estação apresentou os menores valores de desvio padrão e, portanto, a menor variabilidade temporal dentre todas as estações de coleta.

Já a estação de coleta 2 , por outro lado, apresentou os maiores valores médios de condutividade e de todos os nutrientes analisados, bem como a menor concentração média de oxigênio dissolvido, provavelmente por estar mais próxima ao antigo lixão de São Carlos. Assim, corroborando o que foi descrito por Barbosa (2003) ao estudar o rio Uberaba (MG), não foi verificado um gra- 


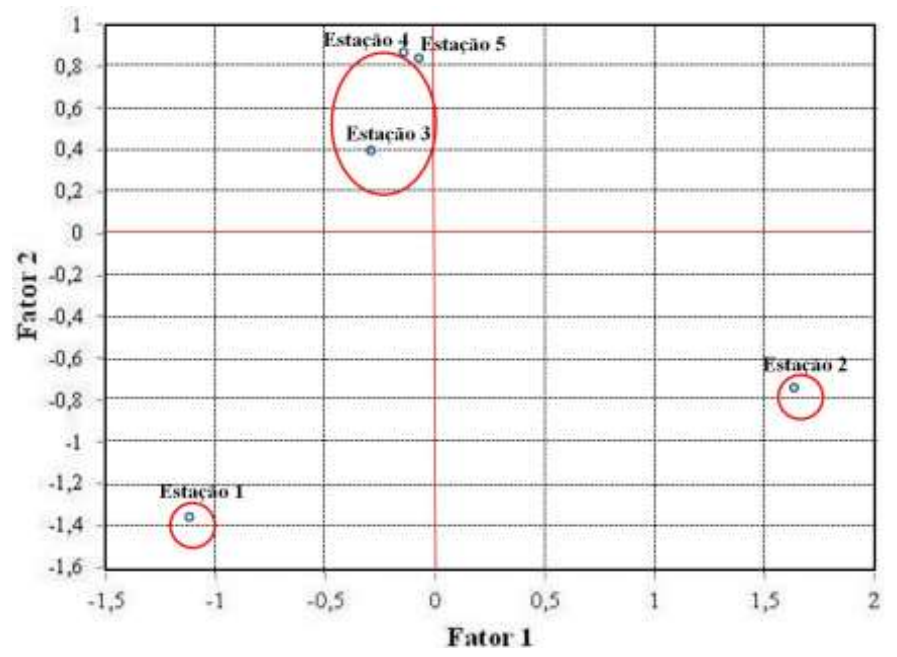

Figura 2. Distribuição espacial das estações de coleta do córrego São José em função das variáveis limnológicas.

diente longitudinal de continuidade no sistema fluvial em estudo, sendo essa continuidade afetada pelas atividades antropogênicas desenvolvidas na bacia hidrográfica, que favorecem a formação de manchas longitudinais.

Assim, embora o lixão tenha sido desativado em 1996 (mais de 10 anos antes da realização desse estudo), verificou-se que a área ainda gera passivos ambientais, influenciando a qualidade da água do córrego São José. A área integra a lista de áreas contaminadas da Companhia Ambiental do Estado de São Paulo (CETESB). Segundo o relatório de 2012 da CETESB, a água subterrânea e superficial, e o subsolo da área estão contaminados devido ao antigo lixão (CETESB, 2012). Velozo (2006) verificou, em 2005, a contaminação do aquífero na área do lixão nas mesmas proporções observadas no ano de 1995. Segundo a autora, grande parte dos resíduos está depositada abaixo do nível d'água e, além disso, o fluxo de contaminantes na área é facilitado pela elevada permeabilidade dos materiais arenosos da região e pela ausência de barreiras menos permeáveis. Shinzato et al. (2013) destacou ainda que, caso não sejam aplicadas na área medidas eficazes de remediação, o antigo depósito de resíduos continuará sendo uma fonte potencial de poluição uma vez que os resíduos sólidos restantes na área armazenam uma grande quantidade de chorume imóvel, com elevadas concentrações de amônia e metais pesados.

Esses resultados geram preocupações não só em relação à preservação da biodiversidade do córrego São José, mas também no que concerne à qualidade do abastecimento de água do município de São Carlos, que é realizado por águas subterrâneas e por água superficial coletada no ribeirão do Feijão, sendo o córrego São José um de seus afluentes (PMSC, 2010). Destaca-se assim a importância do engajamento do poder público e da sociedade civil no sentido de transformar a Política Nacional de Resíduos Sólidos (Lei nº 12.305/2010 - BRASIL, 2010) em um instrumento modificador das atuais práticas de gestão de resíduos sólidos, banindo a disposição de resíduos sólidos em lixões e recuperando as áreas contaminadas devido à disposição inadequada desses resíduos.

\subsection{Composição, distribuição e abundância da comunidade íctica}

Considerando todos os períodos amostrais, foi registrado no córrego São José um total de 168 indivíduos pertencentes a 11 espécies, distribuídas em cinco ordens e nove famílias (Tabela 3). As famílias Characidae e Cichlidae apresentaram duas espécies cada uma, e as demais famílias, apenas uma espécie cada.

Dentre as espécies coletadas, houve predominância da ordem Cyprinodontiformes, seguida da ordem Characiformes. Ainda em termos de abundância, as famílias Poeciliidae e Characidae foram dominantes, abrangendo, respectivamente, $43,5 \%$ e $20,2 \%$ das espécies coletadas durante todo o período amostral. Considerando as coletas individualmente, destaca-se a predominância da família Characidae em abril, com $50 \%$ das espécies coletadas, e da família Poeciliidae em dezembro, com 68,4\% das espécies coletadas (Figura 3).

O cálculo do Índice de Dominância foi aplicado de forma a se verificar quais espécies foram dominantes nas diferentes épocas de coleta, sendo estas separadas conforme suas pluviosidades médias mensais em seca (abril e agosto) e cheia (outubro e dezembro). Seis espécies foram dominantes durante as épocas de seca e cheia: A. altiparanae, A. fasciatus, C. aeneus, G. brasiliensis, Hypostomus sp. e P. vivipara, sendo esta última a espécie mais abundante encontrada (Tabela 4).

Ao considerar as coletas individualmente, verificouse que o mês de outubro foi o que apresentou o menor número de indivíduos coletados (17 indivíduos) e também a menor riqueza (seis espécies). O mês de dezembro foi o que apresentou o maior número de indivíduos coletados (95 indivíduos), mas não a maior riqueza, que foi encontrada em agosto, quando foram coletadas 10 
Tabela 3. Lista taxonômica das espécies encontradas no córrego São José (São Carlos, SP) durante as coletas de abril, agosto, outubro e dezembro de 2007, de acordo com a classificação sistemática proposta por Buckup et al. (2007).

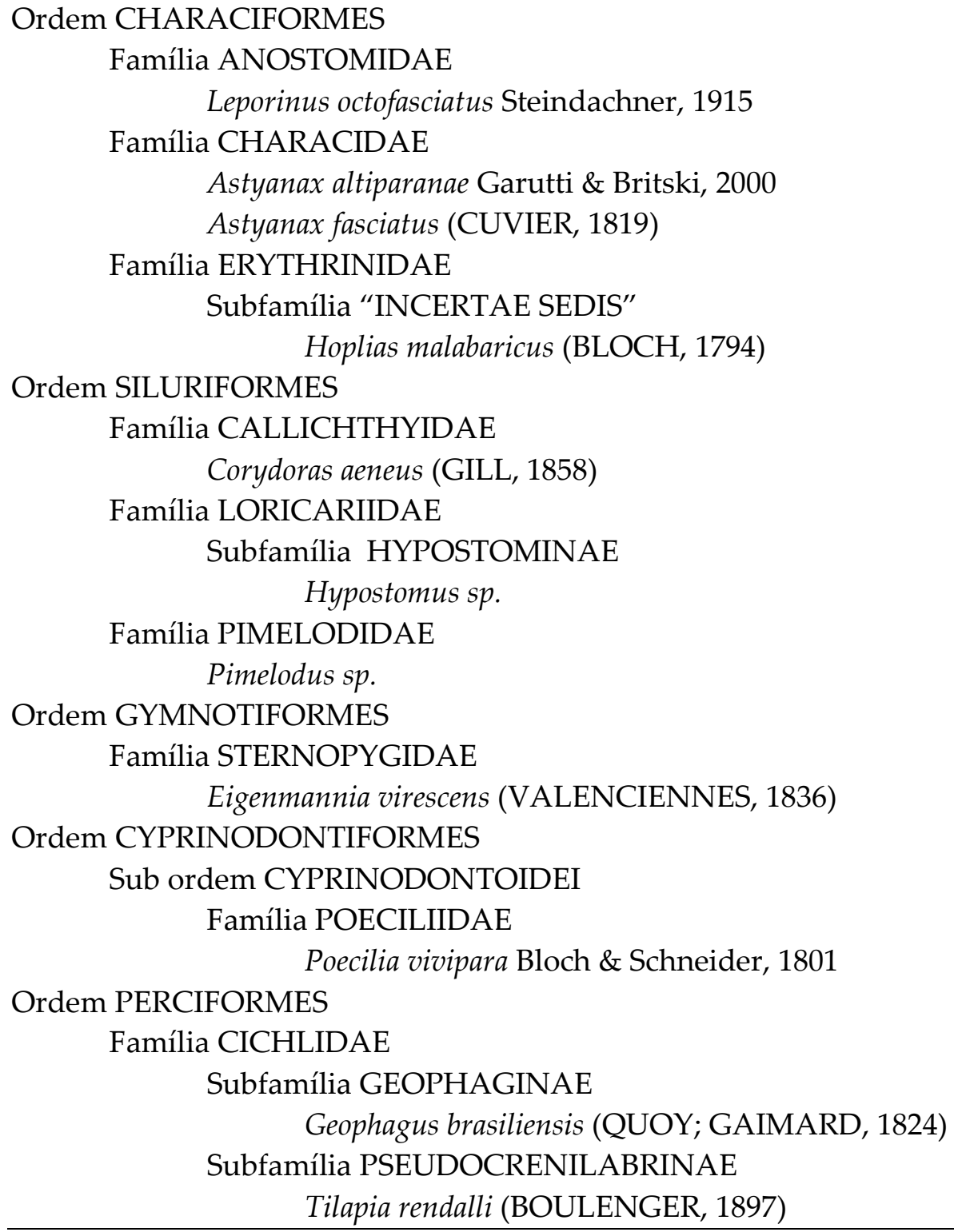

espécies (Tabela 4).

Segundo Lowe-Mcconnell (1999), a diversidade da estrutura do habitat e a sazonalidade são fatores chave que afetam vários aspectos inter-relacionados da vida da comunidade. No córrego São José, os maiores valores de diversidade ocorreram nos meses de agosto e abril (1,99 nat.ind. ${ }^{-1}$ e 1,81 nat.ind. ${ }^{-1}$, respectivamente), que foram os meses de menor precipitação e maior concentração média de oxigênio dissolvido na água. Já em outubro e dezembro, que apresentaram maior precipitação média e menor concentração de oxigênio dissolvido na água, foram registrados menores índices de diversidade (1,68 nat.ind ${ }^{-1}$ e 1,16 nat.ind. ${ }^{-1}$, respectivamente). Com o aumento da precipitação, pode ocorrer um incremento da turbidez da água devido ao carreamento de solos expostos para o corpo d'água. De acordo com Whitefield
(1999), a turbidez pode apresentar um efeito negativo sobre a taxa de crescimento e tamanho da população de peixes e sobre a sobrevivência ao nascer. Além disso, a abundância de peixes está relacionada à heterogeneidade ambiental e à estabilidade do habitat, que é maior no período seco (RIBEIRO NETO et al., 2004).

Para Matthews (1998), a geomorfologia da planície de inundação e sua interação com o canal de drenagem trazem grandes consequências para a vida e alimentação dos peixes. $\mathrm{O}$ autor afirma ainda que as propriedades físicas da água influenciam na ocorrência das espécies ícticas e nos estágios de vida das mesmas. Nesse contexto, mudanças de origem antropogênicas, que influenciam nas taxas e nos processos dos sistemas lóticos, mudando sua estrutura química ou física, geralmente trazem consequências em longo prazo para a comunidade de peixes. 


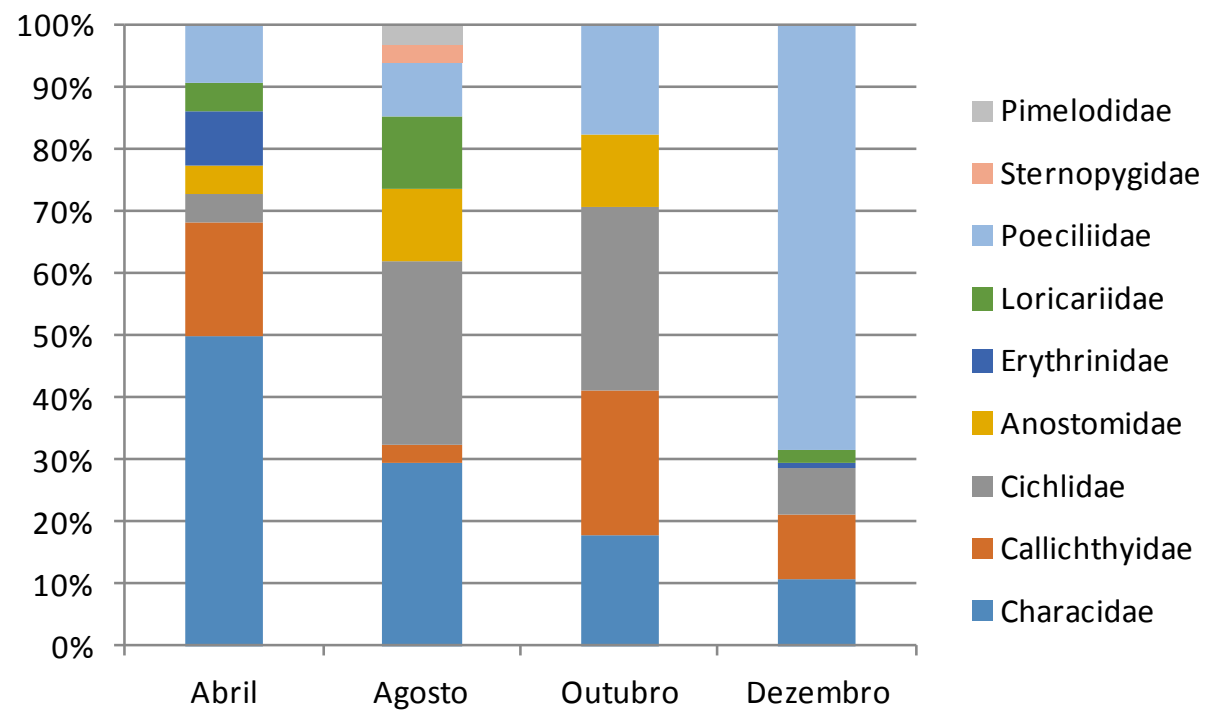

Figura 3. Abundância relativa das famílias de peixes coletadas no córrego São José (São Carlos, SP) durante as quatro coletas realizadas (abril, agosto, outubro e dezembro de 2007).

Tabela 4. Espécies de peixes registradas no córrego São José, com seus respectivos nomes científicos e vulgar, abundância em cada um dos períodos amostrais e classificação referente ao índice de dominância (ID), sendo D: dominante; BD: baixa dominância em pelo menos um dos períodos considerados (seca e cheia) e R: raro.

\begin{tabular}{|c|c|c|c|c|c|c|c|}
\hline Nome científico & $\begin{array}{l}\text { Nome } \\
\text { Vulgar }\end{array}$ & Abril & Agosto & Outubro & Dezembro & Total & $\begin{array}{c}\text { Classificação } \\
\text { ID }\end{array}$ \\
\hline $\begin{array}{l}\text { Astyanax } \\
\text { altiparanae }\end{array}$ & Lambari & 3 & 1 & 2 & 4 & 10 & $\mathrm{D}$ \\
\hline Astyanax fasciatus & Lambari & 8 & 9 & 1 & 6 & 24 & $\mathrm{D}$ \\
\hline Corydoras aeneus & Coridoras & 4 & 1 & 4 & 10 & 19 & $\mathrm{D}$ \\
\hline $\begin{array}{l}\text { Geophagus } \\
\text { brasiliensis }\end{array}$ & Cará & 1 & 8 & 5 & 6 & 20 & $\mathrm{D}$ \\
\hline $\begin{array}{c}\text { Leporinus } \\
\text { octofasciatus }\end{array}$ & Ferreirinha & 1 & 4 & 2 & 0 & 7 & $\mathrm{BD}$ \\
\hline Hoplias malabaricus & Traíra & 2 & 0 & 0 & 1 & 3 & $\mathrm{BD}$ \\
\hline Hypostomus sp. & Cascudo & 1 & 4 & 0 & 2 & 7 & $\mathrm{D}$ \\
\hline Poecilia vivipara & Guarú & 2 & 3 & 3 & 65 & 73 & $\mathrm{D}$ \\
\hline $\begin{array}{c}\text { Eigenmannia } \\
\text { virescens }\end{array}$ & Tuvira & 0 & 1 & 0 & 0 & 1 & $\mathrm{R}$ \\
\hline Tilapia rendalli & Tilápia & 0 & 2 & 0 & 1 & 3 & $\mathrm{BD}$ \\
\hline Pimelodus sp & Bagre & 0 & 1 & 0 & 0 & 1 & $\mathrm{R}$ \\
\hline Abundância total & & 22 & 34 & 17 & 95 & 168 & \\
\hline
\end{tabular}


As estações 1, 2 e 5 foram as que apresentaram maiores índices de riqueza e abundância nos quatro períodos analisados, sendo que em três coletas (agosto, outubro e dezembro) não foi coletado nenhum indivíduo no ponto 4. A abundância dos indivíduos nas coletas de abril e dezembro (meses em que houve maior precipitação na semana de coleta) foi maior na estação mais próxima da nascente. Isto pode estar relacionado ao fato de que no período chuvoso muitas espécies migram para regiões de cabeceira ou para a planície inundada em busca de alimento, abrigo e condições adequadas para reprodução (LOWE-MCCONNELL, 1999).

As diferenças de riqueza de espécies entre as cinco estações estudadas podem estar relacionadas também à heterogeneidade ambiental. As áreas de remanso nos rios facilitam a deposição de fragmentos lenhosos advindos da vegetação marginal, e isso pode propiciar a formação de ambientes mais ricos em microhabitats, que são utilizados como abrigo contra predadores por muitas espécies de peixes (MATTHEWS, 1998). Os recursos alimentares alóctones, como os insetos terrestres, também podem ficar mais tempo disponíveis para os peixes, uma vez que não são rapidamente carreados rio abaixo. Dessa forma, trechos ao longo do canal do rio nos quais a velocidade da água é menor representam um ambiente mais estável, onde a ausência de um fluxo forte exige menor gasto de energia dos organismos para sua permanência no local (ALLAN, 1995). Assim, o fato de não serem encontradas espécies em três coletas na estação 4 pode ser atribuído à falta de microhabitats que serviriam de abrigo para as espécies nessa estação.

Na estação 2 foi encontrada uma elevada abundância de espécies tolerantes à poluição como, por exemplo, $P$. vivipara, que é encontrada com frequência em ambientes bastante degradados (CASATTI; FERREIRA, 2009; CUNICO et al., 2012). Isto pode estar relacionado à existência de ambientes de remanso nessa estação e ao aporte de matéria orgânica proveniente do antigo lixão de São Carlos, que serviria de alimento para os peixes.

Vale destacar também a presença de uma espécie de tilápia (T. rendalli) na estação 5 . As tilápias são provenientes da África e do Oriente Médio, e são espécies oportunistas, que apresentam grande capacidade de adaptação, toleram uma grande variedade de condições ambientais

Tabela 5. Categorias tróficas das espécies de peixes coletadas no córrego São José (São Carlos, SP) e principais itens alimentares encontrados em seus estômagos durante as quatro coletas realizadas (abril, agosto, outubro e dezembro de 2007).

\begin{tabular}{ccc}
\hline Nome científico & Categoria trófica & Principais itens alimentares encontrados \\
\hline Astyanax altiparanae & Onívora & Detritos, fragmentos de inseto e material \\
vstyanax fasciatus & Onívora & Detritos e fragmentos de inseto \\
Corydoras aeneus & Detritívora & Detritos \\
Geophagus brasiliensis & Insetívora & Fragmentos de inseto \\
Leporinus octofasciatus & Bentófaga & Larvas de Chironomidae \\
Hoplias malabaricus & Piscívora & Fragmentos de peixes \\
Hypostomus sp. & Iliófaga & Lodo \\
Poecilia vivipara & Detritívora & Detritos \\
Eigenmannia virescens & Carnívora & Fragmentos de peixes (escamas) \\
Tilapia rendalli & Onívora & Fragmentos de insetos e peixes, e material \\
Pimelodus sp. & Onívora & vegetal \\
\hline
\end{tabular}


e apresentam altas taxas reprodutivas (CANONICO et al., 2005). A introdução no ambiente de espécies exóticas como as tilápias pode causar importantes alterações na estrutura das comunidades locais, colocando em risco a existência de espécies nativas devido à predação e competição por recursos alimentares (POMPEU; ALVES, 2003; CANONICO et al., 2005).

\subsection{Análise da dieta dos peixes}

Em relação aos hábitos alimentares, as espécies de peixes foram agrupadas em sete categorias tróficas, de acordo com o recurso alimentar predominante em seus estômagos (Tabela 5). A dieta predominante foi a onívora, que ocorreu em quatro espécies (Astyanax altiparanae, Astyanax fasciatus, Tilapia rendalli e Pimelodus sp.), seguida pela detritívora, que foi característica de duas espécies (Corydoras aeneus e Poecilia vivipara).

Através da análise do biovolume do conteúdo estomacal dos peixes, foram estimados os itens presentes em maior quantidade na alimentação das espécies encontradas, sendo o item predominante os fragmentos de inseto, seguido de detritos e material vegetal. Verifica-se, desse modo, a grande quantidade de detrito disponível e a importância dos itens de procedência alóctone (vegetais e insetos) na dieta das espécies de peixes do córrego São José.

De maneira geral, nas espécies menores não houve preferência por algum item alimentar específico, caracterizando, desta forma, indivíduos com um hábito alimentar generalista, o que possibilita uma melhor condição de sobrevivência das espécies. Segundo Valduga et al. (2009), a maioria dos peixes tropicais não apresenta dietas especializadas ou regimes alimentares específicos. Esta flexibilidade, associada a possíveis adaptações morfológicas relacionadas com a alimentação, permite que eles explorem diversos nichos e recursos em seu habitat. Além disso, a existência de espécies generalistas reduz a competição interespecífica, favorecendo a coexistência de diferentes espécies e a manutenção da alta diversidade da ictiofauna (ANDRADE et al., 2007).

Alguns fatores relacionados às categorias tróficas podem ser considerados indicativos da qualidade do sistema. As populações de carnívoros do topo da cadeia trófica, por exemplo, tendem a declinar ou até mesmo desaparecer quando a qualidade dos corpos de água diminui. Já as espécies invertívoras são utilizadas muitas vezes como indicadoras de ambientes degradados (KARR, 1981).

Em estudo realizado por Resende et al. (1998) no rio Miranda (MS), foi confirmada a importância dos peixes detritívoros para a pré-mineralização da matéria orgânica presente no lodo, atuando na depuração dos cursos de água sujeitos à poluição ambiental. Os peixes iliófagos, segundo Gneri e Angelescu (1951), têm papel fundamental no ambiente porque facilitam a decomposição da matéria orgânica existente no lodo por micro-orga- nismos, acelerando a reciclagem de nutrientes. Isto pode explicar a elevada abundância da espécie Hypostomus $s p$. na estação 2 , que apresentou a maior concentração média de nutrientes.

\section{Conclusão}

Após mais de 10 anos da desativação do antigo lixão do município de São Carlos, os resíduos ainda influenciam as características físicas e químicas do córrego São José, aumentando a concentração de nutrientes e a condutividade elétrica da água e, consequentemente, reduzindo a concentração de oxigênio dissolvido na estação de coleta a jusante do antigo lixão. Além disso, nesta estação, houve a predominância de espécies de peixe tolerantes à poluição e de espécies classificadas em relação à categoria trófica como illiófagas e detritívoras. Esses resultados ratificam a relação existente entre as características limnológicas do córrego, a estrutura da comunidade de peixes presente no mesmo e a ocupação do seu entorno, destacando a relevância da inativação dos lixões ainda existentes no Brasil e da recuperação das áreas contaminadas por depósitos de resíduos sólidos.

\section{Agradecimentos}

Os autores agradecem ao técnico Marcelo Nogueira pelo auxílio durante as coletas e análises laboratoriais, ao Marcio Bertazi pela confecção do mapa com a localização da área de estudo e à FAPESP (Fundação de Amparo à Pesquisa do Estado de São Paulo) pela bolsa de iniciação científica concedida à segunda autora deste artigo (Processo 2007/54062-6).

\section{Referências}

ALLAN, J. D. Stream Ecology: structure and function off running waters. London: CHAPMAN \& HALL, 1995. 338 p.

\section{APHA - AMERICAN PUBLIC HEALTH}

ASSOCIATION. Standard Methods for the

Examination of Water and Wastewater. 19 Ed. New York: APHA, 1995. 1268 p.

ANDRADE, D. F.; PEREIRA, C. L.; ANGELINI, R.; LIMA, F. P. Nicho Trófico de Duas Espécies do Gênero Astyanax (Characidae) no Rio Corrente, Sudoeste de Goiás. In: VIII CONGRESSO DE ECOLOGIA DO BRASIL, 2007, Caxambu. Anais... Caxambu: SEB, 2007. p. 1-2.

ARGENTON, E. C. Limnologia, balneabilidade e impactos ambientais: uma análise temporal e 
espacial na represa do Lobo (Broa), Itirapina/Brotas - SP. 2004. 146 f. Dissertação (Mestrado) - Escola de Engenharia de São Carlos, Universidade de São Paulo, São Carlos.

ATHAYDE JÚNIOR, G. B.; NÓBREGA, C. C.; GADELHA, C. L. M.; SANTANA, N. C. B.; COSTA, M. D. Principais usos da água do rio Sanhauá na área de influência do antigo lixão do Roger: proposta de revisão de enquadramento do rio. Revista Ambiente e Água, Taubaté, v. 3, n. 3, p. 128142, 2008.

BARBOSA, D. S. Limnologia do rio Uberaba (MG) e a utilização de macroinvertebrados bentônicos como bioindicadores das modificações ambientais. 2003. 158 f. Dissertação (Mestrado) - Escola de Engenharia de São Carlos, Universidade de São Paulo, São Carlos.

BEAUMORD, A. C. As comunidades de peixes do rio Manso, Chapada dos Guimarães, MT: uma abordagem ecológica numérica. 1991. $108 \mathrm{f}$. Dissertação (Mestrado) - Universidade Federal do Rio de Janeiro, Rio de Janeiro.

BRASIL. Conselho Nacional do Meio Ambiente - CONAMA. Resolução Conama nº 357, de 17 de março de 2005. Dispõe sobre a classificação dos corpos de água e diretrizes ambientais para o seu enquadramento, bem como estabelece as condições e padrões de lançamento de efluentes, e dá outras providências. 2005. Disponível em: http://www.mma.gov.br/port/conama/legiabre. cfm?codlegi=459. Acesso em: 13 de março de 2014.

BRASIL. Congresso. Lei no 12.305 de 2 de agosto de 2010. Institui a Política Nacional de Resíduos Sólidos; altera a Lei n⿳0 9.605, de 12 de fevereiro de 1998; e dá outras providências. Disponível em: http://www.planalto.gov.br/ccivil_03/_ato20072010/2010/lei/112305.htm. Acesso em: 13 de março de 2014.

BRITSKI, H. A.; SATO, Y.; ROSA, A. B. S. Manual de identificação de peixes da bacia do São Francisco. Brasília: Câmara dos Deputados, Coordenação de Publicações - CODEVASF, Divisão de Piscicultura e Pesca, 1984. 143 p.

BUCKUP, P. A.; MENEZES, N. A.; GHAZZI, M. S. Catálogo das espécies de peixes de água doce do Brasil. Rio de Janeiro: Museu Nacional, 2007. 195 p.

CANONICO, G. C.; ARTHINGTON, A.; MCCRARY, J. K.; THIEME, M. L. The effects of introduced tilapias on native biodiversity. Aquatic
Conservation: Marine and Freshwater ecosystems, v. 15, n. 5, p. 463-483, 2005.

CASATTI, L.; FERREIRA, C. A fish-based biotic integrity index for assessment of lowland streams in southeastern Brazil. Hydrobiologia, v. 623, p. 173-189, 2009.

CASTRO, R. M. C.; CASATTI, L.; SANTOS, H. F.; MELO, A. L. A.; MARTINS, L. S. F.; FERREIRA, K. M.; GIBRAN, F. Z.; BENINE, R. C.; CARVALHO, M.; RIBEIRO, A. C.; ABREU, T. X.; BOCKMANN, F. A.; PELIÇÃO, G. Z.; STOPIGLIA, R.; LANGEANI, F. Estrutura e composição da ictiofauna de riachos da bacia do rio Grande no estado de São Paulo, sudeste do Brasil. Biota Neotropical, v. 4, n. 1, p. 1-39, 2004.

CETESB - Companhia Ambiental do Estado de São Paulo. Áreas contaminadas: relação de áreas contaminadas, 2012. Disponível em: http:// www.cetesb.sp.gov.br/userfiles/file/areascontaminadas/2012/municipios.pdf. Acesso em: 13 de março de 2014.

CUNICO, A. M.; FERREIRA, E. A.; AGOSTINHO, A. A.; BEAUMORD, A. C.; FERNANDES, R. The effects of local and regional environmental factors on the structure of fish assemblages in the Pirapó Basin, Southern Brazil. Landscape and Urban Planning, v. 105, p. 336-344, 2012.

ELIS, V. R.; ZUQUETTE, L. V. Caracterização geofísica de áreas utilizadas para disposição de resíduos sólidos urbanos. Revista Brasileira de Geociências, v. 32, n. 1, p. 119-134, 2002.

GADOTTI, R. F. Avaliação da contaminação das águas superficiais e subterrâneas adjacentes ao "lixão" da cidade de São Carlos. 1997. 144 f. Dissertação (Mestrado) - Escola de Engenharia de São Carlos, Universidade de São Paulo, São Carlos.

GNERI, F. S.; ANGELESCU, V. La nutricion de los peces iliofagos. Rev. Inst. Nac. Invest. de La Cien. Naturales, v. 2, n. 1, p. 1-44, 1951.

GOLTERMAN, H. L.; CLYMO, R. S.; OHNSTAD, M. A. M. Methods for physical and chemical analysis of freshwaters. 2. ed. Oxford: Blackwell Scientific Publications (I.B.P. Handbook), 1978. 213 p.

IBGE - INSTITUTO BRASILEIRO DE GEOGRAFIA E ESTATÍSTICA. Pesquisa Nacional de Saneamento Básico 2008. Rio de Janeiro, 2010. 219 p.

KARR, J. R. Assessment of biotic integrity using fish 
communities. Fisheries, v. 6, n. 6, p. 21-27, 1981.

KAWAKAMI, E.; VAZZOLER, G. Método gráfico e estimativa de índice alimentar aplicado ao estudo de peixes. Bol. Inst. Oceanogr., v. 29, p. 205-207, 1980.

KOROLEFF, F. Determination of nutrients. In: Methods of seawater analysis. GRASSHOFF, K. (Ed.). Verlag Chemie Weinhein, 1976. p. 117-181.

KREBS, C. J. Ecological methodology. New York: Harper \& Row Publishers, 1989.

KULIKOWSKA, D.; KLIMIUK, E. The effect of landfill age on municipal leachate composition. Bioresource Technology, v. 99, p. 5981-5985, 2008.

LOWE-MCCONNELL, R. H. Estudos Ecológicos de Comunidades de Peixes Tropicais. (Trads.: Vazzoler, A.E.A. de M.; Agostinho, A.A.; Cunnhingham, P.T.M.). São Paulo: EDUSP, 1999, p. 19-38.

MACKERETH, F. J. H.; HERON, J.; TALLING, J. F. Water analysis: some revised methods for limnologists. Ambleside: Freshwater Biological Association, 1978, 120 p.

MAGURRAN, A. E. Diversidad ecológica y su medición. Barcelona: Vedra, 1989. 200 p.

MALHEIROS, C. H.; HARDOIM, E. L.; LIMA, Z. M.; AMORIM, R. S. S. Qualidade da água de uma represa localizada em área agrícola (Campo Verde, MT, Brasil). Revista Ambiente e Água, Taubaté, v. 7, n. 2, p. 245-262, 2012.

MATTHEWS, W. J. Patterns in freshwater fish ecology. Massachusetts: Chapman \& Hall, 1998. $756 \mathrm{p}$.

PMSC - Prefeitura Municipal de São Carlos. Investigação detalhada e avaliação de risco da área do antigo lixão Fazenda Santa Madalena. $2^{\underline{o}}$ relatório bimestral. Secretaria Municipal de Habitação e Desenvolvimento Urbano - SMHDU. São Carlos, 2010. 114 p.

POMPEU, P. dos S.; ALVES, C. B. M. Local fish extinction in a small tropical lake in Brazil. Neotropical Ichthyology, v. 1, n. 2, p. 133-135, 2003.

PORTO, M. F. S.; JUNCA, D. C. M.; GONÇALVES, R. S.; FILHOTE, M. I. F. Lixo, trabalho e saúde: um estudo de caso com catadores em um aterro metropolitano no Rio de Janeiro, Brasil. Caderno de
Saúde Pública, v. 20, n. 6, p. 1.503-1.514, 2004.

PRADO, H.; OLIVEIRA, J. B.; ALMEIDA, C. L. F. Comparative study on phosphorus and nitrogen transport in the Paraná, Paraguay and Bermejo rivers. Limnologia e Manejo de Represas. Séries: Monografias em Limnologia. São Paulo. ACIESP. v. 1, n.1, p. 91-117, 1981.

RESENDE, E. K.; PEREIRA, R. A. C.; ALMEIDA, V. L. L. Peixes herbívoros de planície inundável do rio Miranda, Pantanal, Mato Grosso do Sul, Brasil. Corumbá: EMBRAPA - Boletim de pesquisa, 1998. $24 \mathrm{p}$.

RIBEIRO, M. C. L. B. Conservação da integridade biótica das comunidades de peixes do Ribeirão Gama: Área de Proteção Ambiental (APA) Gama/ Cabeça de Veado, Brasília, DF. 1994. 176 f. Tese (Doutorado) - Universidade Estadual Paulista "Júlio de Mesquita Filho", Rio Claro.

RIBEIRO NETO, F. B.; ISHIKAWA-FERREIRA, L.; HÖFLING, J. C. A. Comunidade de peixes do Reservatório de Salto Grande. In: Espíndola, E. L. G., Leite, M. A., Dornfeld, C. B. (Eds). Reservatório de Salto Grande (Americana, SP): caracterização, impactos e propostas de manejo. São Carlos: Rima. 2004, 484 p.

RIOS, L. Estudo limnológico e fatores ecológicos em ribeirões e córregos da bacia hidrográfica do ribeirão do Feijão (Estado de São Paulo). 1993, 146 f. Dissertação (Mestrado) - Escola de Engenharia de São Carlos, Universidade de São Paulo, São Carlos.

SHALINI, S. S.; JOSEPH, K. Nitrogen management in landfill leachate: Application of SHARON, ANAMMOX and combined SHARONANAMMOX process. Waste Management, v. 32, p. 2385-2400, 2012.

SHINZATO, M. P.; SCHALCH, V.; WENDLAND, E. C. Resíduos Sólidos x Recursos Hídricos: estudos no lixão Santa Madalena, São Carlos, SP. In: XI SIMPÓSIO DE RECURSOS HÍDRICOS DO NORDESTE, 2012, João Pessoa. Anais... João Pessoa: ABRH, 2012. p. 1-17.

SHINZATO, M. P.; MARTINS, L. G. B.; SCHALCH, V.; WENDLAND, E. Characteristics of landed material from an abandoned waste dump in Brazil. In: Fourteenth International Waste Management and Landfill Symposium, 2013, Sardinia (Italy). Anais... Sardinia: IWWG, 2013. p. 1-8.

SINGH, R. K.; DATTA, M.; NEMA, A. K. A new 
system for groundwater contamination hazard rating of landfills. Journal of Environmental Management, v. 91, p. 344-357, 2009.

TEIXEIRA, D. Caracterização limnológica dos sistemas lóticos e variação temporal e espacial de invertebrados bentônicos da bacia do ribeirão do Feijão (São Carlos - SP). 1993. 210 f. Dissertação (Mestrado) - Escola de Engenharia de São Carlos, Universidade de São Paulo, São Carlos.

TOGORO, E. S. Qualidade da água e integridade biótica: estudo de caso em um trecho fluminense do rio Paraíba do Sul. 2006. 184 f. Dissertação (Mestrado) - Universidade do Estado do Rio de Janeiro, Rio de Janeiro.

VALDUGA, M. O.; FORGATI, M.; FREITAS, M.; SABCHUK, N.; PEDREIRO, M. R. D.; KREBSBACH, P.; RIOS, S. F.; DONATTI, L. Ecologia Alimentar de Astyanax spp. coletados no Rio Corumbataí - Pitanga/PR. In: IX CONGRESSO DE ECOLOGIA DO BRASIL, 2009, São Lourenço. Anais... São Lourenço: SEB, 2009. p. 1-3.

VELOZO, R. Caracterização geológico-geotécnica do lixão desativado de São Carlos-SP, com o auxílio da geofísica. 2006. 177 f. Dissertação (Mestrado) Escola de Engenharia de São Carlos, Universidade de São Paulo, São Carlos.

VON SPERLING, M. Introdução à qualidade das águas e ao tratamento de esgotos. 3 ed. Belo Horizonte: Departamento de Engenharia Sanitária e Ambiental (DESA), Universidade Federal de Minas Gerais, 2005. 452 p.

WHITFIELD, A. K. Ichthyofaunal assemblages in estuaries: a South African case study. Reviews in Fish Biology and Fisheries, v. 9, n. 2, p. 151-186, 1999. 